\title{
O ISLÃ E A IMIGRAÇÃO SENEGALESA CONTEMPORÂNEA NO SUL DO BRASIL
}

\author{
Guilherme Curi*
}

Resumo: 0 artigo traz reflexões a partir de um estudo comunicacional sobre a recente imigração senegalesa na região sul do Rio Grande do Sul, no município de Rio Grande, iniciada na segunda década de 2000 e a importância da prática religiosa para essa comunidade. A base teórica para este estudo está fundamentada principalmente nos pressupostos de Muniz Sodré $(2006$, 2014) e Stuart Hall (2003). Foi realizada uma pesquisa de campo por meio de observação participante e entrevistas semiestruturadas com representantes da comunidade senegalesa na região sul do estado. A relação entre religião, representação e migração em contexto de diáspora mostra-se como prolongamento de vínculos, circulação e interação entre as comunidades locais e imigrantes.

Palavras-chave: Migrações transnacionais. Islã. Cultura contemporânea. Comunicação. Senegaleses.

\section{INTRODUÇÃO}

0 presente trabalho, que faz parte de uma pesquisa de pós-doutorado em Comunicação pela Universidade Federal de Santa Maria, busca refletir e analisar a recente imigração senegalesa na região sul do estado do Rio Grande do Sul, mais especificamente no município de Rio Grande, iniciada na segunda década de 2000, e sua relação com a religião islâmica. Esse fenômeno acontece no sul global, termo sugerido pela literatura contemporânea (JUNG, 2019; BAENINGER et al., 2018) muito utilizado em estudos pós-coloniais e transnacionais, ao contemplar o surgimento de novos caminhos de grupos migratórios de paises em desenvolvimento em todo o mundo, em nivel intercontinental, como resultado das mudanças econômicas e geopolíticas nas regiões que estabeleceram novas ligações.

Posto isso, uma das principais características da comunidade senegalesa é a prática religiosa do islã. Assim como muitos árabe-brasileiros que aqui residem há quase um século, a

\footnotetext{
* Pós-doutor em Comunicação pela Universidade Federal de Santa Maria (UFSM). Doutor em Comunicação e Cultura pela Universidade Federal do Rio de Janeiro (UFRJ), com bolsa de pesquisa CNPq (2016-2018). Mestre em Sociologia pela University College Dublin (UCD), Irlanda. Professor colaborador do Programa de Pós-Graduação em Comunicação da UFSM.
} 
maioria dos senegaleses que chegam ao Brasil são muçulmanos. De acordo com Luís Mauro Sá Martino (2016), a relação entre mídia e religião na sociedade contemporânea ganha novas dimensões. Segundo o autor, promovidas pelos ambientes digitais, essas ligações modificam a lógica da mídia e as práticas da religião acabam permeando áreas como a cultura, a economia e a política, entre outros aspectos da vida em sociedade. Embora pareça muitas vezes uma questão de fé individual, a religião é vivida em público, ou seja, é uma prática social, e isso a torna um importante tema para as Ciências Sociais, em especial, para a Comunicação, pois "como a pessoa religiosa se veste, fala, vive com os outros, escolhe seus relacionamentos afetivos ou mesmo profissionais está, em alguma medida, ligado às suas crenças" (MARTINO, 2016, p. 9).

Ainda, a cidade aqui é percebida como o imperativo estrutural de tornar comuns as diferenças ou de unir os opostos, o que, em sua dinâmica, se torna palco das mediações socioculturais tão determinantes no campo comunicacional (SODRÉ, 2014). Rio Grande, principal campo da pesquisa, possui cerca de 209 mil habitantes e está localizada no extremo sul do país, entre a Lagoa Mirim, a Lagoa do Patos e o Oceano Atlântico. É um dos portos mais antigos do Brasil, primeira capital do estado do Rio Grande do Sul, com uma história populacional marcada pelo fluxo de diferentes comunidades étnicas nos últimos séculos, entre eles: europeus (portugueses, espanhóis, gregos, franceses, alemães e ingleses), africanos, árabes e asiáticos.

No âmbito empírico, foi realizada uma pesquisa de campo com observação participante, registros fotográficos, por compreender a importância das imagens e da representação desses imigrantes no contexto de diáspora, e entrevistas semiestruturadas com os imigrantes senegaleses, além da análise das práticas comunicacionais e religiosas.

\section{A COMUNICAÇÃO TRANSCULTURAL PARA COMPREENDER AS DIFERENTES DIÁSPORAS}

Atualmente, de acordo com o novo relatório. "World migration report 2020" (INTERNATIONAL ORGANIZATION FOR MIGRATION, 2020), cerca de 24 milhões de pessoas vivem em outros paises diferentes dos seus, o que representa 3,3\% da população mundial. Estima-se que, caso o crescimento se mantenha, em 2050, o número de migrantes em todo o mundo poderá chegar a 405 milhões. Ainda, segundo dados do Governo Federal, publicados no relatório "Refúgios em números" (SECRETARIA NACIONAL DE JUSTIÇA, 2018), apenas no ano passado, 179 mil estrangeiros pediram a regularização no Brasil, dos quais 5.564 são do continente africano - alguns deles com pedido de refúgio.

Logo, a reorganização nas tendências e características dos fenômenos migratórios exigem uma reavaliação dos paradigmas para a compreensão e análise das migrações transnacio- 
nais ou internacionais, à medida que as novas modalidades de deslocamentos humanos não são mais caracterizadas apenas por sua expressão numérica, mas marcadas por uma rede complexa de significados, decorrentes de diferentes diásporas. 0 fenômeno migratório atual é assim caracterizado, de acordo com Elhajji (2012, p. 34): "laços de sentido que se tecem e se densificam, costurando a teia simbólica global que vem cobrindo o mundo e reformulando a sua morfologia social e humana - discursiva, imaginaria e biológica". Nessa teia simbólica global, está a comunicação, arena fundamental onde se negocia o status social, cultural e político das migrações. De acordo com Sodré (2006), o desafio da comunicação enquanto práxis social seria suscitar uma compreensão. Em outras palavras, um "conhecimento e ao mesmo tempo uma aplicação do que se conhece, na medida em que os sujeitos implicados no discurso se orientam nas situações concretas da vida, pelo sentido comunicativamente obtido" (SODRÉ, 2006, p. 14).

Ainda, para Sodré (2014), a comunicação revela-se como principal forma de organização na sociedade contemporânea. Revela-se, segundo o autor, porque comunicação significa, de fato, em sua radicalidade, "o fazer organizativo das mediações imprescindiveis ao comum humano, a resolução aproximativa das diferenças pertinentes em formas simbólicas" (SODRÉ, 2014, p. 15), ou seja, uma interação subjetiva, em que devemos atentar para as diferentes formas de colocar-se em comum, concatenar-se no ponto em que a vinculação humana seria o problema central da comunicação.

Em suma, o que se propõe aqui é uma perspectiva transcultural, o que, de acordo com Sodré, é diferente de sobreposições multiculturalistas, "em que o gosto do pensamento pelo exótico admite harmonizações, mas sempre sob a égide da lógica hegemônica" (SODRÉ, 2014, p. 22). Significa, segundo o autor, um desafio que induz à prática de uma dialogia semiótica, em outras palavras, diferente de um diálogo entre formações que ambicionem ser verdadeiras, inertes e estanques - uma "lógica do trans ou do vaivém através dos limiares do sentido [...] que não são necessariamente conciliatórias ou harmônicas, mas que abrem caminhos para novos termos das disputas de sentido" (SODRÉ, 2014, p. 22).

Ainda nesse sentido, Hall (2003) traz uma fundamental observação ao salientar que o conceito fechado de diáspora se apoia sobre uma concepção binária de diferença, "uma espécie de fronteira de exclusão, dependente da construção de um outro ou de uma oposição rígida entre o dentro e o fora" (HALL, 2003, p. 32). Segundo o autor, o conceito de différance, de Jaques Derrida, torna-se de extrema utilidade para uma melhor compreensão das diferentes diásporas, pois atenta para um processo que não funciona por meio de "binarismos, fronteiras veladas que não separam [...], mas também lugares de passagem e significados que são posicionais e relacionais, sempre em deslize ao longo de um espectro sem começo nem fim" (HALL, 2003, p. 33).

Nas próximas seções, será realizada uma breve análise descritiva do desenvolvimento dos processos migratórios dos senegaleses e suas relações com as novas mídias. Na parte final, 
iremos descrever a pesquisa de campo que foi realizada na mesquita da cidade de Rio Grande, além de relatar e analisar as questões que surgiram a partir das entrevistas com os integrantes da comunidade senegalesa. Por questões éticas, não utilizaremos os reais nomes dos entrevistados.

\section{PRINCIPAIS CARACTERÍSTICAS DA IMIGRAÇÃO SENEGALESA NO BRASIL}

A diáspora senegalesa ocorreu em diferentes continentes no último século. Os locais mais antigos aos quais se direcionam os fluxos migratórios são Europa e vários países da África Ocidental. Já na América do Norte e na América do Sul, a imigração senegalesa é mais recente. Assim como lembra Tedesco (2019), os senegaleses chamam a atenção nos locais de destino por suas manifestações religiosas, linguísticas, culturais e associativismo. Além disso, a prática do comércio informal, nas regiões centrais das cidades, assim como também acontece em Rio Grande, tem "provocado conflitos e embates e ao mesmo tempo revelado dinamismos-inventividades e estratégias mercantis" (TEDESCO, 2019, p. 2).

Apesar de o país localizado na costa oeste africana não ter guerras internas, como outros paises do continente, o Senegal sofre com vários problemas decorrentes da desigualdade social. A falta de emprego pode ser identificada como um dos fatores estruturais mais importantes para a saída do pais de nascimento. "Senegal é bom, mas falta trabalho" - é uma frase recorrente nas falas dos entrevistados.

Destarte, sabe-se que a imigração senegalesa no Brasil é recente. De acordo com Jung (2019), apenas 21 senegaleses foram registrados oficialmente no país no começo dos anos 2000. No entanto, a partir de 2010, os números aumentaram. Em 2013, por exemplo, 970 senegaleses foram registrados. Já em 2014, esse número praticamente dobrou, chegando a 1.687. No total, de acordo com dados do Governo Federal, 7.206 solicitações de refúgio foram feitas por senegaleses entre os anos de 2010 e 2015 (ALTO COMISSARIADO DAS NAÇÕES UNIDAS PARA REFUGIADOS [ACNUR], 2021). Ao passar pela fronteira, a maioria requer o pedido de refúgio, o que garante a possibilidade de estadia regular no Brasil, prevista por lei, e de obtenção de carteira de trabalho. No entanto, após certo período, alguns senegaleses têm seus pedidos negados, o que resulta em muitas dificuldades sociais, ou ainda se encontram com situação migratória pendente. A imigração senegalesa no Brasil é caraterizada ainda por ser principalmente masculina, com predomínio da faixa etária entre 19 e 50 anos (JUNG, 2019, p. 58).

Ainda, segundo Jung (2019), o crescimento da imigração senegalesa no Brasil ocorreu em um período em que grande parte do mundo passava por uma forte crise econômica, cujos impactos afetaram o Brasil alguns anos depois. Além disso, a securitização das fronteiras europeias no Mediterrâneo se intensificou e as políticas de imigração na Europa e nos Esta- 
dos Unidos tornaram-se mais rigorosas. 0 Brasil, em vista da facilidade de entrada nesse periodo, tornou-se um caminho possivel para os imigrantes africanos.

Embora não se saibam os números exatos dos dados sobre a entrada de senegaleses em território brasileiro, de acordo com Jung (2019), os pedidos de refúgio e a integração no mercado de trabalho formal permitem supor um aumento significativo entre 2010 e 2015. 0 Sistema Nacional de Cadastro e Registro de Estrangeiros (Sincre), segundo o pesquisador, registrou 824 novas inscrições de senegaleses entre 2010 e 2017 (JUNG, 2019). Os estados com o maior número foram Rio Grande do Sul, Paraná e São Paulo. No entanto, esses dados apenas permitem estimar o tamanho da comunidade senegalesa. Segundo o pesquisador, apesar do ainda constante movimento de vendedores ambulantes nas cidades, acredita-se que uma boa parte dos senegaleses já tenha deixado o Brasil.

Em suma, para Jung (2019) e Tedesco (2019), podemos dividir a emigração recente do país do Senegal para o Brasil em três períodos. 0 primeiro acontece até meados de 2012, quando não mais de mil senegaleses estiveram em território nacional e, para vários deles, o Brasil foi mais uma etapa na trajetória migratória antes de migrar para outros países do norte. 0 segundo começa em 2013 e dura até o fim de 2015, periodo de maior fluxo, quando os senegaleses entraram no Brasil principalmente vindos do Equador, que na época permitia que esses imigrantes entrassem na América Latina sem qualquer regulamento de visto. Já a terceira fase, a atual, é caracterizada por duas questões principais: as mudanças da política imigratória do Equador, que resulta também na dificuldade de imigração senegalesa para o Brasil, e a crise econômica e política brasileira, que resultou na saída de um considerável número de senegaleses do país. Ou seja, crise política que resulta em crises econômica, laboral, social e migratória.

Por meio das entrevistas realizadas com os imigrantes senegaleses, podemos perceber essas mudanças mencionadas pelos pesquisadores. 0 entrevistado 1, que morava no Brasil havia sete anos, na cidade de Rio Grande - RS, após ter carteira assinada, começou a trabaIhar no comércio de rua local. É casado e tem dois filhos. No trecho seguinte, é possivel destacar as razões de migrar do Senegal para o sul do País.

O Senegal não é um país muito, muito pobre, mas que não é tão bom também. Eu sou formado, fiz universidade, tenho diplomas, eu era professor de francês e árabe, falo cinco idiomas, mas não conseguia fazer dinheiro suficiente para sustentar minha família. Esse é o motivo de todos os senegaleses estarem aqui. Nos saímos para tentar uma vida melhor e fizemos contatos com as pessoas que já saíram. 0 Brasil é um dos países com as portas mais abertas, já tentei ir pra França, Itália e Espanha, mas sempre foi bem difícil de conseguir visto ou entrar clandestinamente nessas cidades, mesmo arriscando a vida. Mas em 2013 o Brasil era visto como uma oportunidade para os senegaleses, teve um projeto dos haitianos que estavam entrando por Rio Branco e os senegaleses se juntaram para poder entrar no 
Brasil, pra buscar uma vida melhor [...]. A vida está bem difícil lá, não temos guerra, problemas graves, mas tá bem difícil (ENTREVISTADO 1).

De fato, o imigrante entrevistado é um entre alguns milhares de senegaleses que vivem hoje no Rio Grande do Sul. Infelizmente, não existem dados concretos e oficiais no estado, pois alguns permaneceram indocumentados após terem o pedido de refúgio negado. No entanto, segundo organizações não governamentais e associações dos próprios imigrantes, calculava-se que cerca de 3,9 mil senegaleses estavam residindo no Rio Grande do Sul até o começo de 2019, e cerca de 2 mil estariam na capital, Porto Alegre. Já de acordo com o líder da Associação dos Senegaleses de Rio Grande - RS, aproximadamente 150 imigrantes senegaleses vivem hoje na cidade. A outra grande parte está na Serra Gaúcha, principalmente na cidade de Caxias do Sul e adjacências. A tendência, como veremos a seguir, é que uma parte desses imigrantes esteja deixando o estado.

\section{0 islã no Senegal e na diáspora}

De fato, para compreendermos a complexa diáspora senegalesa além das questões sociais e econômicas, é necessário analisarmos as práticas religiosas e a inserção coletiva desses imigrantes. Atualmente, mais de 90\% da população do Senegal é de orientação muçulmana. Entre as várias vertentes de seguidores do islamismo estão os sufis, de caráter místico, como o mouridismo, uma das confrarias mais representativas no contexto da diáspora senegalesa. De acordo com Lacomba (2001), um dos primeiros pesquisadores a investigar a prática islâmica dos senegaleses na nova diáspora, as formas de estruturação e organização das confrarias entre os muçulmanos senegaleses na diáspora demonstram o potencial do mouridismo no contexto de imigração.

\footnotetext{
Apesar da natureza comunitária, o sistema mouride também inclui várias iniciativas individuais. Por exemplo, a mediação feita pela confraria entre os imigrantes e a sociedade de acoIhimento a qual possibilita ajudar os jovens dotados de iniciativa comercial a beneficiar-se do sistema de solidariedade mouride e assim alcançar objetivos pessoais (LACOMBA, 2001, p. 184).
}

Ainda, Dias afirma que as confrarias muçulmanas pertencem ao "universo de manifestações misticas coletivas do Islã e são, de forma estruturada, a mais antiga e importante expressão da espiritualidade muçulmana, o sufismo'" (DIAS, 2007, p. 2). Já Sambe (2015),

\footnotetext{
1 - Essa vertente se caracteriza pela "interpretação contemplativa do Islã"; pela centralidade dada à "exegese do Alcorão e à glosa da Sunnna"; pelo caráter pedagógico de acesso ao conhecimento religioso; pela importância atribuída aos "dons ditos sobrenaturais dos fundadores das confrarias e dos seus sucessores (barak); e por práticas de aspecto sincrético" (DIAS, 2007, p. 2).
} 
aponta que há séculos as confrarias sufis no Senegal, além de desempenharem um papel fundamental na expansão do islã e na adaptação às culturas africanas, exercem certo protagonismo político e social. Nos séculos XVIII e XIX, as confrarias faziam parte de importantes teocracias muçulmanas e do combate à conquista colonial francesa. Desde finais do século XIX, os dirigentes dessas confrarias se tornaram os principais interlocutores entre os muçulmanos e o Estado. Aqui, emerge o papel dos marabus, ou marabouts, termo que, segundo Sambe (2015, p. 125), designa que, desde o período colonial, no Senegal e nos países vizinhos, os dirigentes das confrarias (califas e xeiques), "são hoje, como no passado colonial, uma referência essencial no jogo político senegalês".

Outro elemento de destaque são as dahiras, termo que significa círculo, ou seja, uma associação local de membros da confraria mouride. De acordo com Tilmann Heil, que fez um minucioso estudo etnográfico em uma dahira no Rio de Janeiro, ela representa uma forma organizativa "onipresente no mundo dos senegaleses [...], um lugar de encontro, de oração e recitação dos poemas do Cheikh Ahmadou Bamba, mas também de prestação de apoio mútuo, de troca de informações e até de interações comerciais" (HEIL, 2018, p. 113).

Por fim, um dos mais importantes elementos para a compreensão da cultura senegalesa na diáspora é a presença e o significado simbólico e vinculativo do Cheikh Ahmadou Bamba, fundador do mouridismo. De acordo com Rossa, o sistema que o líder do mouridismo projetou era baseado em uma educação voltada para transformar o caráter e o comportamento de seus discípulos seguidores. 0 carisma e a reputação de Bamba atraíam muitos discípulos e, com o passar dos anos, chamou a atenção do poder colonial francês, que não compactuava "com o proselitismo da confraria e a atitude pouco cooperante do seu líder com a administração da época" (ROSSA, 2019, p. 296). Com isso, o poder colonial francês o acusou de subversão e obrigou-o a deixar o país por duas vezes, a primeira no Gabão, entre 1895 e 1902, e a segunda na Mauritânia, entre 1902 e 1907 (ROSSA, 2019). Assim, as provações que Bamba enfrentou fizeram que aumentasse ainda mais a admiração de seus seguidores. Uma das heranças religiosas mais importantes deixadas pelo seu líder aos mourides é o Grand Magal de Touba (Grande Festa de Touba), que é a principal celebração mouride. Segundo a pesquisadora, "a celebração é um pedido feito pelo próprio Cheikh Ahmadou Bamba aos seus discípulos, em comemoração ao aniversário de sua primeira partida para o exílio no Gabão" (ROSSA, 2019, p. 297). Assim, o Grand Magal de Touba, comemorado no dia 18 do mês de Sáfar do calendário muçulmano em todo mundo, transformou-se em um importante feriado religioso, celebrado por meio de diferentes práticas, como cantos de khassidas, recitação do Alcorão e orações. Nesse dia, cerca de 2 milhões de seguidores visitam a cidade de Touba, e o evento é transmitido e visto em tempo real por meio de mídias digitais por todos os praticantes do mouridismo em situação de diáspora.

A celebração é realizada por comunidades senegalesas em diversas cidades ao redor do mundo. Logo, é de suma importância destacarmos os usos e as apropriações de novas tec- 
nologias móveis e a transmissão ao vivo do Grand Magal de Touba, assim como a circulação de imagens nos quatro cantos do mundo, as quais "aludem aos sentidos de co-presença e de mobilidade, evidenciando o caráter transnacional do próprio Mouridismo e de suas ressignificações a partir do passado colonial do Senegal e em sua dimensão diaspórica" (BRIGNOL; COSTA, 2018, p. 25). Por meio das transmissões da festa do Grand Magal de Touba, é reforçada a memória do exílio do xeique e o papel da religião como resistência diante do domínio francês, enquanto, concomitantemente, se atualiza a cerimônia como marca da presença de migrantes no Brasil e em outros paises. 0 Grand Magal de Touba configura-se, assim, como um evento transnacional pelo sentido comunicativo, de partilha. As mesmas práticas, costumes e recitais "são experimentados em diferentes cidades do mundo, no mesmo dia, com a partilha de informações e de fotografias, com os usos da internet pelos adeptos da religião" (BRIGNOL; COSTA, 2018, p. 25). 0 recital das Khassidas, por exemplo, não acontece apenas entre aqueles que estão presentes fisicamente, mas também entre as pessoas conectadas via internet, seja por aplicativo WhatsApp ou redes sociais.

\section{PESQUISA DE CAMPO}

Na cidade de Rio Grande, a 318 km ao sul da capital Porto Alegre, iniciamos nosso trabaIho de campo no começo de 2019, quando passamos a entrevistar representantes da comunidade senegalesa e a participar dos cultos religiosos na mesquita da cidade, nosso campo principal. De acordo com o presidente da Associação dos Senegaleses de Rio Grande (entrevistado 2), os primeiros imigrantes chegaram em 2013.

\footnotetext{
Eu cheguei com mais nove pessoas, no mesmo dia conseguimos dez vagas de serviço, um mês depois chegaram mais pessoas e conseguiram emprego. Estava fácil de conseguir trabalho com carteira assinada. Trabalhei por três anos na fábrica de peixes Torquato Pontes. Alguém chegava e era empregado. Estamos aqui pra trabalhar, ganhar dinheiro, quem tem carteira assinada vai nos dar a mão. Mas com o tempo a gente percebeu que estava mudando a situação, os senegaleses foram demitidos e por isso começamos a vender, mesmo sabendo que não era legal. Já tivemos mais de 250 senegaleses aqui, agora muitos já foram embora. Agora somos em torno de 150, menos da metade tem carteira assinada, cerca de 70. A situação mudou, está bem difícil. Se está difícil para os brasileiros, imagina pra nós (ENTREVISTADO 2).
}

0 relato retrata aquilo que Jung (2019) descreve como as três mudanças de fases da imigração senegalesa no Brasil nos últimos anos. Vale ressaltar que Rio Grande foi uma das cidades mais afetadas pela crise econômica e política brasileira. No começo da segunda 
década de 2000, o projeto federal de construção de plataformas de petróleo da Petrobras no estaleiro do Porto Novo de Rio Grande gerou mais de 30 mil empregos diretos e indiretos, 0 que fez que a economia da cidade crescesse vertiginosamente. 0 quase total declínio da indústria naval em meados de 2016, com muitas demissões e o fechamento de comércios locais logo após o impeachment da presidente Dilma Rousseff, gerou uma drástica crise econômica e social na cidade. Só a empresa Engevix Construções Oceânicas, uma das empreiteiras contratadas para as obras do Polo Naval, demitiu 3,2 mil funcionários de uma vez (RIO GRANDE, 2016). Ainda, de acordo com dados da prefeitura da cidade, em 2017 o município deixou de arrecadar $\mathrm{R} \$ 70$ milhões (BUENO, 2017).

No entanto, mesmo com a crise, muitos senegaleses permaneceram no município. Apontamos aqui algumas hipóteses para esses imigrantes terem continuado na cidade. A primeira é a flexibilidade, apesar de ainda haver dificuldades com o poder público local em relação ao comércio de rua informal.

Figura 1 Imigrante senegalês no comércio informal na Praça Tamandaré, Rio Grande - RS

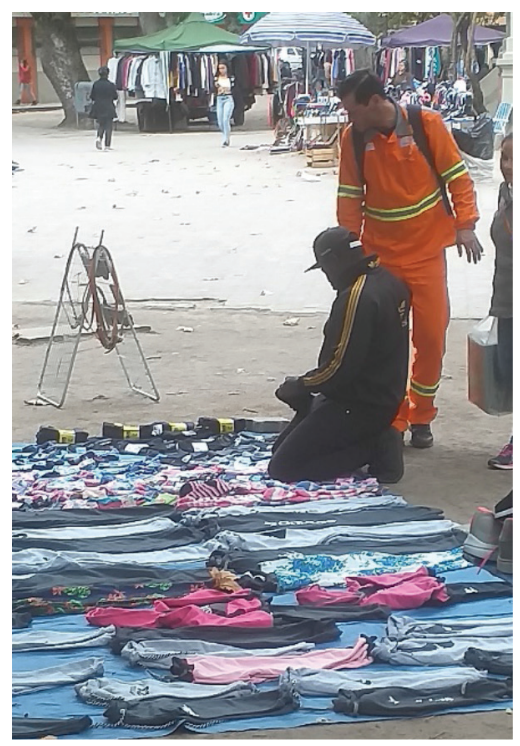

Fonte: Acervo do autor.

De acordo com alguns dos entrevistados, a maioria dos fiscais da prefeitura municipal não confisca os produtos comercializados. Outras hipóteses podem ser enumeradas: 1. durante o verão, Rio Grande, cidade costeira, atrai cerca de 150 mil turistas para a praia, o que faz que, durante os meses de dezembro, janeiro e fevereiro, os migrantes senegaleses possam também comercializar mercadorias na orla marítima; 2. alguns entrevistados apontaram não haver tantos casos de racismo em comparação com outras cidades gaúchas. Tal fato se dá, 
talvez, por Rio Grande ter uma maior miscigenação de culturas por causa do porto marítimo e o fluxo constante e histórico de imigrantes na cidade, como os árabe-brasileiros que aqui residem, ponto-chave desta investigação. Em Pelotas, por exemplo, munícipio vizinho, em recente pesquisa etnográfica junto à comunidade senegalesa que vivia na cidade entre os anos de 2015 e 2016, as pesquisadoras Simone Roberto e Patrícia Pinheiro apontam que os imigrantes senegaleses foram duramente reprimidos no exercício das suas atividades comerciais. Em determinadas ocasiões, relatam que "a repressão instituída pela Guarda Municipal implicou em um forte uso de aparato armado, como: gás de pimenta, armas de choque e ameaças à mão armada" (ROBERTO; PINHEIRO, 2019, p. 130).

Figura 2 Imigrante senegalês na praia do Cassino, Rio Grande - RS

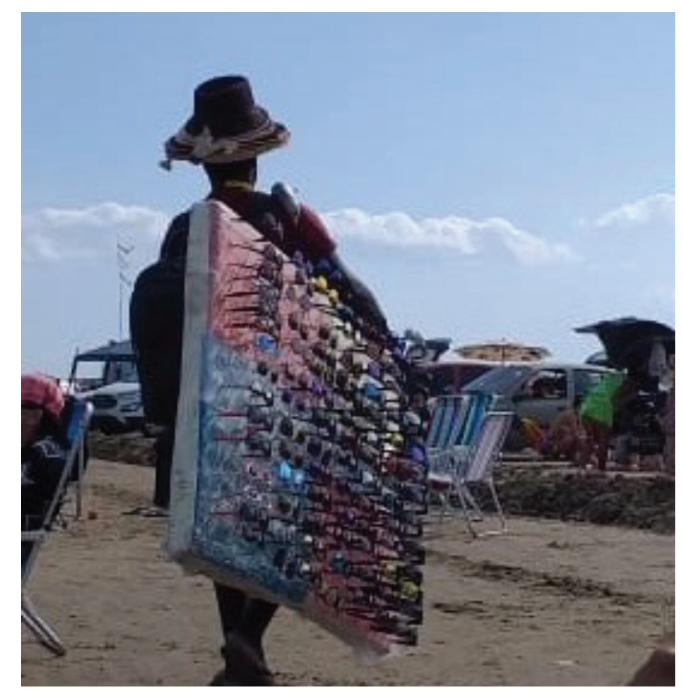

Fonte: Acervo do autor.

0 seguinte relato de um dos senegaleses entrevistados, um homem de 29 anos que morava em Rio Grande havia quatro anos, nos dá indícios da confirmação dessas hipóteses:

Em Rio Grande há mais compreensão, não há barbárie. Mas em outras cidades estão mais rigorosos, com mais agressões, é mais violento. Fiquei com raiva na minha primeira vez que vi e passei por isso em Pelotas. As pessoas de Rio Grande são mais flexíveis e simpáticas. Nessas cidades que nos tratam mal, a maioria já saiu (ENTREVISTADO 3).

Desse modo, entre os meses de janeiro e setembro de 2019, passamos a acompanhar em diferentes sextas-feiras, na primeira hora da tarde, os cultos na mesquita localizada no centro da cidade, além de participar de reuniões religiosas de ambas as comunidades. 
De acordo com um dos líderes da comunidade palestina (entrevistado 4), homem de 54 anos, filho de palestinos, o grupo que se reúne na mesquita faz parte da Sociedade Beneficente Islâmica Árabe Palestina Brasileira e fora criado havia cerca de 18 anos, a partir de encontros e resoluções que aconteceram durante o Fórum Social Mundial, em Porto Alegre, no ano de 2001. 0 Fórum foi um evento organizado por movimentos sociais de diferentes continentes com o objetivo de elaborar e construir alternativas para uma transformação social global, com o slogan "Um outro mundo é possivel".

A atual mesquita, localizada em uma casa alugada na Rua Carlos Gomes, no centro da cidade, foi criada há cerca de três anos. Antes funcionava em outro estabelecimento, também no centro da cidade, onde a comunidade permaneceu por 15 anos. Os árabe-brasileiros muçulmanos que frequentam a mesquita são de orientação sunita ${ }^{2}$, assim como a maioria, que representa cerca de $85 \%$ dos muçulmanos no mundo. Ao todo, na comunidade, somam-se cerca de 20 pessoas praticantes, todos homens, com idades entre 25 e 65 anos. A maior parte deles é proveniente de famílias palestinas que migraram para Rio Grande há quase 60 anos. Há também dois brasileiros convertidos ao islã.

Na mesquita, todos falam em árabe, ainda que os sermões sejam realizados em árabe e português. A mesma frase é lida duas vezes, nas diferentes línguas. 0 árabe, mesmo não sendo a língua oficial de ambos os países, naquele local se torna a língua principal, um instrumento central de vinculação.

Constatou-se também que, em alguns momentos, os imigrantes senegaleses registram os cultos religiosos via celular (smartphones), assim como acontece nas festas do Grand Magal de Touba - algo mais presente entre eles do que entre os muçulmanos locais. Várias vezes foi observado que os senegaleses enviam por meio dos celulares imagens para o Senegal e outros paises, em tempo real, demonstrando, assim, uma forma de manter vínculos com a terra natal, com a circulação de imagens ao redor do mundo, que aludem aos sentidos de mútua presença e mobilidade, evidenciando, mais uma vez, o caráter transnacional do mouridismo e de suas ressignificações. Constatamos, assim, que a mediação tecnológica na experiência religiosa de migrantes senegaleses não somente traz implicações para os sentidos das múltiplas temporalidades migrantes, mas torna-se constitutiva da própria migração na contemporaneidade.

Ainda, em uma das entrevistas, um dos imigrantes senegaleses contou que, em todas as sextas-feiras, ao ir à mesquita, sentia-se mais próximo do seu pais: "Quando venho aqui é como eu estivesse indo ao Senegal (ENTREVISTADO 3)". De fato, muitos desses imigrantes

2 - Muçulmanos sunitas se consideram o ramo ortodoxo e tradicionalista do islã. A palavra sunita vem de "Ahl alSunna", ou "as pessoas da tradição". A tradição, nesse caso, refere-se a práticas baseadas em precedentes ou relatos das ações do profeta Maomé e de próximos a ele. Os sunitas veneram todos os profetas mencionados no Corão, mas veem Maomé como o último profeta. 
senegaleses, assim com o entrevistado, trocam suas roupas casuais de trabalho por roupas tradicionais islâmicas momentos antes de adentrarem a mesquita, algo muito simbólico, interpretado por nós como uma espécie de eterno retorno à própria casa. Aqui, Abdelmalek Sayad (1998), referência nos estudos migratórios, nos auxilia na reflexão ao apontar que o estado de migração nunca termina, é condição permanente, composta pela dualidade da presença. Ou seja, ao ocupar um novo lugar, o imigrante/emigrante deixará outro vazio e tornar-se-á, "atopo, sem lugar, deslocado, inclassificável [...] nem cidadão, nem estrangeiro, nem totalmente do lado do mesmo, nem totalmente do lado do outro" (SAYAD, 1998, p. 11).

Figura 3 Momento de oração na mesquita de Rio Grande - RS

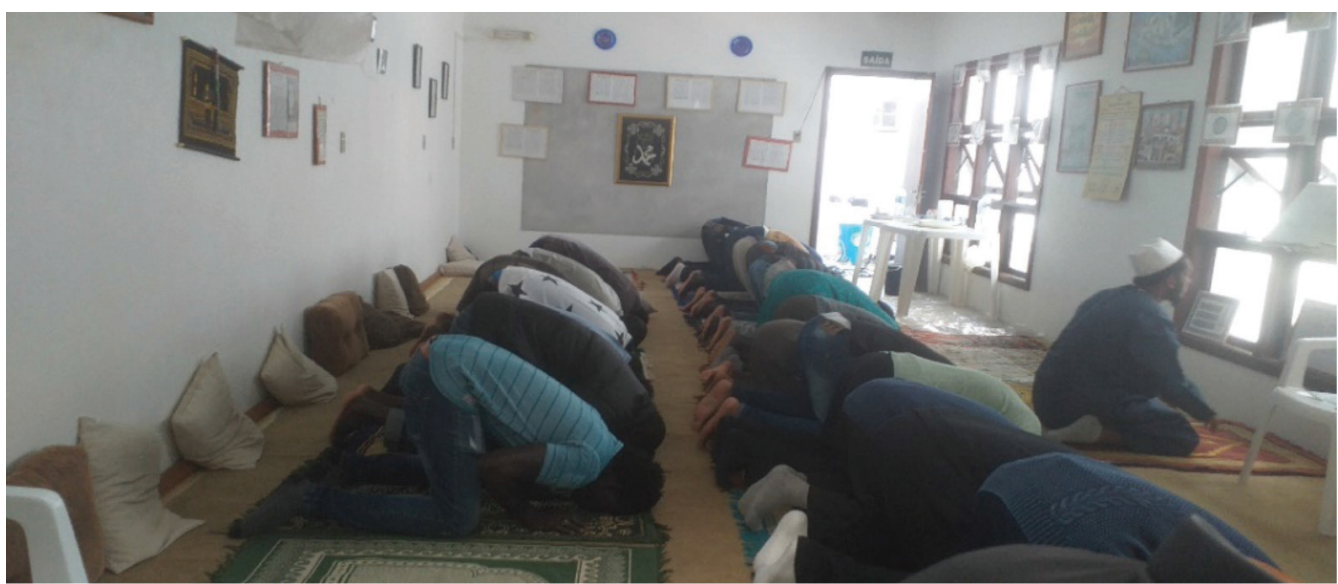

Fonte: Acervo do autor.

Os senegaleses destacaram a importância da liberdade religiosa no Brasil, ainda que a falta de conhecimento da maioria dos brasileiros sobre os preceitos básicos do islamismo tenha sido algo constante nas falas. Sobre as possiveis dificuldades das práticas religiosas na sociedade brasileira, majoritariamente cristã, o entrevistado 4, que trabalha em uma fábrica de peixes e tem 31 anos, e que morava em Rio Grande havia seis anos, comentou:

\footnotetext{
A gente não teve dificuldade para praticar nossa religião. Se a gente tem um evento religioso a gente programa de uma maneira certa para ser para todos. Nós temos uma casa alugada específica para estes eventos religiosos, além da mesquita dos árabes que frequentamos (ENTREVISTADO 4).
}

Ainda, em dois domingos de 2019, ao frequentarmos uma reunião religiosa dos senegeleses, uma dahira, constatamos claras diferenças entre os cultos realizados na mesquita árabe sunita e o mouridismo senegalês. Na ocasião, foram recitados Khassidas, com cantos musi- 
cais em torno de livros que ficavam no centro da sala, além da leitura do Alcorão, na língua árabe. No entanto, nesse dia, cerca de 40 senegaleses estavam presentes e o líder da Associação dos Senegaleses conversou em uolofe com os presentes. Segundo ele, foram tratadas questões relativas à comunidade senegalesa, principalmente sobre os problemas com o comércio de rua local e também sobre a situação de trabalho de alguns imigrantes na fábrica de peixe. Atualmente, cerca de 20 senegaleses trabalham na fábrica, dois com cargos gerenciais.

Heil (2018, p. 127), em estudo sobre senegaleses no Rio de Janeiro, constatou que a dahira, por sua maior estabilidade em decorrência da devoção religiosa, "se manifestou como o centro dessa infraestrutura muçulmana de chegada", fundamental para a constituição e fortalecimento político daquela comunidade.

\section{CONSIDERAÇÕES FINAIS}

Ao longo da pesquisa, podemos constatar alguns importantes elementos comunicacionais, sociais e culturais a partir da análise das práticas religiosas dos senegaleses islâmicos no sul do Brasil.

Assim como já apontado por alguns pesquisadores (LACOMBA, 2001; SAMBE, 2015; ROS$S A, 2019)$, confirmou-se o fato de que as redes de irmandade mouride que se formam na diáspora senegalesa são de extrema importância na imigração e contribuem para a manutenção dos laços de identidade coletiva. Além disso, essas redes podem ser observadas também como espaços de construção e organização política em defesa dos direitos desses imigrantes.

A mesquita, assim, enquanto espaço transnacional e transcultural, para além de um espaço meramente religioso, demonstrou ser a possibilidade para o imigrante senegalês, por meio das práticas midiáticas, efetivar relações sociais a partir de suas próprias múltiplas identidades geradas e as posições simultâneas em diferentes espaços. Ou seja, o imigrante está aqui e lá - algo que, em última instância, auxilia no efetivo enfrentamento das vicissitudes da imigração e dificuldades encontradas no lugar de sua vivência e atuação.

Nesse sentido, a relação entre religião e migração em contexto de diáspora mostrou-se como prolongamento de vínculos, circulação e interação, mais do que como perda marcada pela partida. Em outras palavras, os espaços de prática religiosa transpõem os aspectos espirituais, servindo, também, como um ambiente de proteção. 


\section{Islam and contemporary senegalese immigration in southern Brazil}

Abstract: This article brings reflections from a communicational study on the recent Senegalese immigration in the southern region of Rio Grande do Sul, in the municipality of Rio Grande, which started in the second decade of 2000 and the importance of the religious practice for this community. The theoretical basis for this study is mainly on the assumptions of Muniz Sodré $(2006$, 2014) and Stuart Hall (2003). A field research was carried out with participant observation and semi-structured interviews with representatives of the Senegalese community in the southern region of the state. The relationship between religion, representation and migration in the context of diaspora has shown as the extension of ties, circulation and interaction between local and immigrant communities.

Keywords: Transnational migrations. Islam. Contemporary culture. Communication. Senegalese.

\section{REFERÊNCIAS}

ALTO COMISSARIADO DAS NAÇÕES UNIDAS PARA REFUGIADOS (Acnur). Dados sobre refúgio no Brasil, 2021. Disponivel em: https://www.acnur.org/portugues/dados-sobre-refugio/dados-sobre-refugio-no-brasil/. Acesso em: 20 fev. 2021.

BAENINGER, L. M. et al. (org.). Migrações Sul-Sul. Campinas, SP: Núcleo de Estudos de População "Elza Berquó" (Nepo): Unicamp, 2018.

BRIGNOL, L. D.; COSTA, N. D. Diáspora senegalesa e mediação tecnológica: entre tempos e lugares na observação do Magal de Touba. Contracampo, Niterói, v. 37, n. 1, p. 42-55, 2018.

BUENO, S. R. Rio Grande busca saída à crise dos estaleiros. Valor Econômico, 12 jun. 2017. Disponivel em: https://www.valor.com.br/empresas/5000802/rio-grande-busca-saida-crisedos-estaleiros. Acesso em: 20 out. 2020.

COGO, D.; ELHAJJI, M.; HUERTAS, A. (ed.). Diásporas, migrações, tecnologias da comunicação e identidades transnacionais. Bellaterra: Universitat Autònoma de Barcelona, 2012.

DEMANT, P. O mundo muçulmano. São Paulo: Contexto, 2011.

DIAS, E. C. Senegal: confrarias, contrato social e modernidade. Janus, v. 2, n. 59, p. 41-51, 2007. ELHAJJI, M. Rio de Janeiro - Montreal: conexões transnacionais / ruídos interculturais. In: COGO, D.; ELHAJJI, M.; HUERTAS, A. (ed.). Diásporas, migrações, tecnologias da comunicação e identidades transnacionais. Bellaterra: Universitat Autònoma de Barcelona, 2012. p. 31-42.

ELHAJJI, M.; ESCUDERO, C. Webdiáspora: migrações, TICs e memória coletiva. In: SODRÉ, M.; TEMER, A. C. R. P.; ELHAJJI, M. (org.) Diásporas urbanas: migrantes, viajantes e transeuntes. Goiânia: UFG, 2015. p. 19-41. 
HALL, S. Da diáspora: identidades e mediações culturais. Organização Liv Sovik. Belo Horizonte: UFMG, 2003. Representação da Unesco no Brasil.

HEIL, T. Uma infraestrutura muçulmana de chegada no Rio de Janeiro. Revista Interdisciplinar de Mobilidade Humana-REMHU, v. 26, n. 52, p. 111-129, 2018.

INTERNATIONAL ORGANIZATION FOR MIGRATION. World migration report 2020. 2020. Disponivel em: https://publications.iom.int/books/world-migration-report-2020. Acesso em: 10 dez. 2020.

JUNG, P. R. Desenvolvimento de processos migratórios do Senegal para o Brasil e suas alterações. In: TEDESCO, J. C. (org.). Imigração senegalesa: múltiplas dimensões. Porto Alegre: EST Edições, 2019. p. 45-76. v. 2.

LACOMBA, J. Inmigrantes senegaleses, islam y cofradias. Revista Internacional de Sociología, v. 59, n. 29, p. 163-167, maio/ago. 2001.

LESSER, J. A negociação da identidade nacional: imigrantes, minorias e a luta pela etnicidade no Brasil. São Paulo: Unesp, 2001.

MARTINO, L. M. S. Mídia, religião e sociedade: das palavras às redes digitais. São Paulo: Paulus, 2016.

RIO GRANDE. Ecovix demite 3,2 mil trabalhadores do polo naval de Rio Grande. O Polo Naval é Nosso!, 12 dez. 2016. Disponivel em: http://www.riogrande.rs.gov.br/opolonaval/index.php/ noticias/detalhes+29b „ecovix-demite-32-mil-trabalhadores-do-polo-naval-de-rio-grande-.html. Acesso em: 20 set. 2020.

ROBERTO, S. A. A.; PINHEIRO, P. dos S. Do Senegal a Pelotas, RS: migração, identidade e violência. Século XXI. Revista de Ciências Sociais, v. 9, n. 1, p. 123-158, jan./jun. 2019.

ROSSA, J. Seguidores de Cheikh Ahmadou Bamba: apontamentos etnográficos sobre a vivência da fé no contexto migratório de senegaleses Mourides. In: TEDESCO, J. C. (org.). Imigração senegalesa: múltiplas dimensões. Porto Alegre: EST Edições, 2019. p. 287-312. v. 2.

SAMBE, B. Senegal: un islam local en épocas de globalización religiosa. Nueva Sociedad, n. 257, p. 124-137, 2015.

SANTOS, B. de S. (org.). A globalização e as ciências sociais. São Paulo: Cortez, 2002.

SÃO PAULO. Secretaria Municipal de Direitos Humanos e Cidadania. Somos todos migrantes: acesso a direitos para migrantes e servidores públicos. São Paulo: Secretaria Municipal de Direitos Humanos e Cidadania, 2018. Disponivel em: https://www.justica.gov.br/seus-direitos/refugio/anexos/somos-todos-migrantes.pdf. Acesso em: 20 maio 2020.

SAYAD, A. Imigração ou os paradoxos da alteridade. São Paulo: Edusp, 1998. 
SECRETARIA NACIONAL DE JUSTIÇA. Refúgio em números. 3. ed. Brasilia: Ministério da Justiça 2018. Disponivel em: https://www.justica.gov.br/seus-direitos/refugio/anexos/refasgioem nasmeros_1104.pdf. Acesso em: 20 out. 2020.

SODRÉ, M. As estratégias sensiveis: afeto, mídia e política. Petrópolis: Vozes, 2006.

SODRÉ, M. Ciência do comum. Petrópolis: Vozes, 2014.

TEDESCO, J. C. (org.). Imigração senegalesa: múltiplas dimensões. Porto Alegre: EST Edições, 2019. 